\title{
LLANSOL, LA BOÉTIE, A SERVIDÃO VOLUNTÁRIA E A LIBERDADE DE ESCREVER
}

Bernardo Romagnoli

Bethonico* *bernardorb@gmail.com

Mestre em Estudos Portugueses pela Universidade Nova de Lisboa.
RESUMO: Desejamos nos ver no espelho do poder que determina e prevê. A autonomia é uma resistência a essa vontade. $O$ fazer da escrita como emergência do imprevisível é defesa de práticas "para nada", que não desligam o verbo do corpo, sem imposições de uma suposta comunicação nivelada.

PALAVRAS-CHAVE: liberdade; corpo; escrita.
ABSTRACT: We wish to see ourselves reflected in the mirror of a power which determines and foresees. Autonomy is a resistance to this desire. The craft of writing as the emersion of uncertainty is a defense of "unproductive" practices that do not disconnect the word from the body, without the imposition of an alleged even communication.

KEYWORDS: freedom; body; writing. 
Ninguém te dá quem és.

Llansol Lisboaleipzig I

\section{ESPERANÇA, PARADOXO}

Há horizontes que o humano vislumbra. Não raro contamos com uma farta imaginação ao pensarmos em silêncio sobre a gasta palavra liberdade. Muitas vezes ela olha distante, do horizonte, mas guarda em si o possível - a metamorfose de sua condição de ideal para algo efetivo.

A liberdade irrompe, então, como imagem potencializadora do instante em que não se pode mais adiar, do presente em que se vive de fato, em que se tem poder de decisão. Ela aciona voos. Aparece e desaparece. A liberdade dá apoio à rasura, ao erro, à possibilidade de recomeço, de abundância. Está, portanto, em jogo com a autonomia de quem a invoca E em estreita relação com a busca de uma felicidade. $\mathrm{O}$ suporte da liberdade não é total: é preciso que o corpo de quem procura esteja implicado no fazer que está fazendo.

Felicidade, essa afinação de si. Esse rádio de pilha que quase nunca pega bem, mas que nós insistimos em ligar e ficar procurando sintonia. Resistência. Esperança, um novo princípio da filosofia, como diz Ernst Bloch:
Não falo da esperança como afecto, em oposição a receio, mas da esperança como acto cognitivo, acto de conhecimento [...] Todos os tempos de mudança trazem consigo uma alta percentagem daquilo a que chamei "o ainda-não consciente", com o seu correlativo objectivo e real, "aquilo que ainda não é": o ainda-não de que a matéria do Ser está grávida. [...] Todas as utopias geográficas que conhecemos até hoje falharam... O acesso às origens foi-nos barrado, mas do paraíso correm ainda os rios eternos, com o seu ouro e as suas gemas preciosas, e a própria pedra filosofal...

O transhistórico acto de Bloch desenha uma ampla relação entre a mudança, crise ativadora do porvir, e a força da imagem alquímica com seus rios eternos. A esperança semeia a coragem de não permanecer, enfrentar a metamorfose acolhendo o ruído do impossível. Persevera-se pelo paradoxo de se perseverar. $\mathrm{O}$ acesso foi-nos barrado, entretanto o fluxo não para de chegar à nossa porta.

O paradoxo, contradição aparente, enunciado afastado da doxa - da moral e da obviedade -, funda entre contrários uma troca infinita. O prefixo de origem grega para- indica oposição, mas, se considerarmos o seu significado em vocábulos como "parágrafo", significa proximidade. Tensão imagética em que a interdição e o fluxo, o inimigo e o amigo existem lado a lado, em um
1. BLOCH. Princípio da esperança: uma enciclopédia dos desejos . 
2. LACOUE-LABARTHE. O paradoxo e a mimese, p. 163.

3. LACOUE-LABARTHE. O paradoxo e a mimese, p. 164.

4. LISPECTOR. A paixão segundo $G H$.

5. LLANSOL. Encontro-me no novo, p. 85.
[...] movimento hiperbólico pelo qual se estabelece - provavelmente sem jamais se estabelecer - a equivalência dos contrários - e de contrários levados ao extremo, infinito por direito, da contrariedade. É por isso que a fórmula do paradoxo é sempre a do duplo superlativo: quanto mais louco, mais sábio; o mais louco é o mais sábio. O paradoxo se define pela troca infinita ou pela identidade hiperbólica dos contrários. ${ }^{2}$

O paradoxo opera a lógica abissal da esperança. Nenhuma dialética é capaz de deter a eternidade do paradoxar - ainda que altere uma tese, jamais terá resolução. ${ }^{3}$ Beira a vala do não-compreender.

Em afinidade com o paradoxo, tudo o que não é definitivo a liberdade abraça, porque com ela é possível ir e voltar, vir, dançar, dizer umas palavras para nada, escrever uma carta, dar uma pirueta, enfim, a liberdade é um grande abraço que não quer nos prender.

Como dizia Clarice Lispector, não compreender é sempre mais vasto do que compreender. "É uma benção estranha, como ter loucura sem ser doida."4 Há nesse horizonte abundância, rasura, recomeço, ecoando alguns dos bens elencados por Maria Gabriela Llansol. "[...] bens da Terra que, para mim são cinco:/ O conhecimento, a abundância, a generosidade, o prazer do amante e a alegria de viver."

Não há dúvidas de que as acepções de liberdade são diversas, com problemáticos desdobramentos nos discursos, no tempo.
A resistência a uma situação aprisionante pode sempre ser recuperada na atualização de um horizonte de liberdade. E horizontes de liberdade também podem ser mecanismos de impostura. $\mathrm{Na}$ esteira de todas as retóricas que se utilizam dessa palavra, a história nos lega um imenso resto. Ecos que perduram. Algo sobra enquanto derramamentos de sangue, de textos, de lutas utópicas assolam nossos livros e televisões. Nada disso realmente termina, continuamos a procurar hoje o que muitos seres humanos do passado procuraram. Para Ernst Bloch, a liberdade é "chegar a um mundo em que cada objecto se liberte dos factores alienantes que o acorrentam". ${ }^{6} \mathrm{O}$ que é alienante, entretanto, será uma longa história, mas instintivamente é possível perceber vestígios de um espaço edênico ${ }^{7}$ que possibilita declarações como as de Bloch e as de Llansol -

[...] na história social europeia, jamais nenhum princípio organizador dos homens quer seja o sangue, a raça, o dinheiro, o mérito, a ideologia, se conseguiu impor duradouramente, $\mathrm{e}$ jamais algum deles adquiriu um estatuto metafísico, propiciador de subserviências consentidas. Criámos, assim, um espaço para a evolução do possível e, sobretudo, para a emergência do imprevisível. [...] É minha convicção que, na linguagem dos homens, as palavras que nos libertam do Poder desde sempre lá se encontram disponíveis [...] Que esse pode ser o nosso intento, a utilidade mais óbvia da nossa técnica de artesãos da escrita. ${ }^{8}$

$\begin{array}{lllll}\text { EM TESE } & \text { BELO HORIZONTE } & \text { v. } 19 & \text { N. } 2 & \text { AG0.-0ut. } 2013 \\ \text { BETHONICO. Llansol, La Boétie, a servidão voluntária e a liberdade de escrever P. 226-237 }\end{array}$

6. BLOCH. Princípio da esperança: uma enciclopédia dos desejos sonhados pela humanidade.

7. O espaço edénico é na obra de Llansol convite a uma realidade efetiva, a ser construída com a linguagem, a singularidade e o desconhecido que existem no humano. A linguagem estética não é aqui um Éden que ingenuamente foge do ruído do mundo. O que mais interessa no espaço edênico é a pujança, e não a representação. O conhecimento, a abundância, a generosidade, o prazer do amante $e$ a alegria de viver, bens da Terra para Llansol, não estão separados, "no lugar de" de escrever ou ler. O espaço edênico é alimento às potências do corpo que existe aqui e agora - voz rasurada por uma história que insiste em separar o pensamento da escuta dos afetos, cultivando o medo. >>>

8. LLANSOL. Nós estamos de volta, p. 92-93. 
9. A. BORGES. Eu leio assim este livro, p. 10.

10. A. BORGES. Texto para a restante vida, p. 98.

O Éden, no entanto, jamais chegará inteiro. A impermanência dos princípios organizadores europeus cria um espaço para a evolução do possível, sobretudo para a emergência do imprevisível. Ninguém fará um livro sagrado do qual tenhamos que decorar frases. Não presta para ser fielmente catalogado.

Resistente aos despedaçamentos históricos, a conceitos de família, nação, raça, colonialismos, autoritarismos, distante desses egoísmos do eu - o sangue, o dinheiro, o mérito, a visibilidade, a ideologia -, há uma liberdade conhecida através da necessidade de silêncio. Práticas inseridas em comunidade, porque podem ser acessadas sempre em qualquer sala, praça, soleira, mas afastadas e muitas vezes solitárias, na medida em que não são sobre controlar palavras.

O texto de Llansol chama de Poder a instância controladora construída por dois pares de verbos, "o falar e negociar o produzir e explorar". ${ }^{9}$ O controle das palavras pela autoridade que sempre mantém a vantagem dá-se por enunciados que sustentam que devemos muito àqueles que nos cobram reiterações de sua superioridade. Fantasmas que colonizam nossas frases. "Por que não estranhar que se chame poderoso a esse (que outro nome lhe dar?) que nos tomava por partes do seu fantasma insatisfeito e podia pegar em nós abertamente, e pode pegar em nós clandestinamente, como meio subserviente do seu encanto?"10

O imaginário que suporta as hierarquias define a representação do que é "razoável", "bom”, "consciente" - onde cultivamos o desejo de ordenar e o desejo de obedecer. Com efeito, no século XVI, Étienne de La Boétie legou-nos um discurso que permanece atualíssimo, no qual é demonstrada uma voluntariedade das relações servis, tidas como naturais. E Pierre Clastres, prefaciando uma edição portuguesa do texto, salienta que o desejo de se submeter é antes uma vontade não-deliberada, impulso de se ver no espelho do poder. ${ }^{11}$

O tempo assiste à permanência do poderoso pegando em nós clandestinamente. Não se trata da pessoa de um tirano ou de um senhor. Aí encontram-se o micropoder, as instâncias que performam o pertencimento, que exigem que se corresponda a uma constante avaliação da razoabilidade do que dizemos, do que fazemos, de como nos vestimos, que corpo temos etc. Já no século XVI de La Boétie, o controle do poderoso, o controle gramatical encontra sua legitimação no seio de nossa existência: "Onde iria ele buscar os olhos com que vos espia se não lhos désseis?” ${ }^{2}$

\section{SORRIA, VOCÊ ESTÁ SENDO FILMADO}

A consignação dos olhos formata a apreensão dos cotidianos, assimila um conjunto de hábitos de obediência que passam a ser considerados naturais. Desejo de servir que está na espécie humana, considerando que "é natural ao homem
7. >>> Com efeito, a crítica efetuada por Llansol enxerga um encontro entre a encenação política e histórica e $\mathrm{o}$ aborto das sensibilidades. A convicção é a de que o espaço edênico "nâo e fixo, como sugere a tradição, mas elaboravel segundo o desejo criador do homem" (LLANSOL. espaço edenico, p. 146) Como diz Augusto Joaquim, a obra de Llansol e "dos raros textos a dar deliberadamente voz às forças inintencionais (vulgo, bombardeio constante de estímulos sensoriais). Que eu saiba, é nele que, pela primeira vez, as massas de início são centrais. Vemo-las agir, evoluir, pensar, sofrer, convictas de que o espaço edénico - o Grande Exterior -, além de indestrutível, é o único destino para uma espécie comunicante, contradizendo à letra a pretensão dos grupos estratégicos que persistem em definir para o humano um destino de morte e de impotência."

(JOAQUIM. Nesse lugar, p. 208.)

11. CLASTRES Liberdade, infortúnio, inominável.

12. LA BOÉTIE. Discurso sobre a servidão voluntária, p. 25.
EM TESE 
13. LA BOÉTIE. Discurso sobre a servidão voluntária, p. 37.

14. LA BOÉTIE. Discurso sobre a servidão voluntária, p. 37. o ser livre e o querer sê-lo; mas está igualmente na sua natureza ficar com certos hábitos que a educação lhe dá”. ${ }^{13}$

A educação, no entanto, é uma prática que muitas vezes não tem conseguido acompanhar a velocidade das mudanças de comportamento em nossa sociedade. Basta lembrarmos como rapidamente ruíram certezas nesse campo, na caminhada dos séculos. Muitos pais esqueceram-se de como se nega algo aos filhos; a escola, hoje sem palmatória, esforça-se em vão por engessar a atenção dos alunos, cada vez mais flutuante e entretida com celulares.

O próprio autor do texto citado escreveu, em 1548: "eu creio firmemente que, se nós vivêssemos de acordo com a natureza e com os seus ensinamentos, seríamos naturalmente obedientes aos pais, submissos à razão e de ninguém escravos". ${ }^{14}$ Há bem pouco tempo considerações como essa faziam muito sentido, na medida em que a autoridade não poderia deixar de ser concebida como a grande provedora da verdade. Como se não houvesse, anterior à própria autoridade, um intrincado desde sempre. La Boétie, por exemplo, se contradiz ao defender, junto com a mencionada natureza obediente-livre, que a servidão vem de um esquecimento da liberdade que os antepassados do escravo tiveram a oportunidade de conhecer. É natural obedecer aos pais e à razão, mas ao mesmo tempo a servidão mantém-se no conformismo hereditário.
Ao longo do século XX, ataques aos pedestais, aos cânones, aos gêneros e às classificações em geral desdobraram a tradição da ruptura em muitas direções. Claro está, como queria Oscar Wilde, que o natural é uma pose difícil de ser mantida. E também para Llansol “[...] na história social europeia, jamais nenhum princípio organizador dos homens [...] se conseguiu impor duradouramente, e jamais algum deles adquiriu um estatuto metafísico, propiciador de subserviências consentidas." 15

Manchas, vislumbres, a emergência do imprevisivel, a evolução do possível, instituintes que são, não servem para serem imutáveis. Não trazem um princípio que se deva reter centralmente - o imprevisível, o possível são impossíveis de serem conhecidos como são. O convite à liberdade de si vem de um lugar de experimentação, deriva. $\mathrm{Na}$ margem do razoável, do bem, da posse. Como se disse, o poderoso pega em nós clandestinamente. Há um encanto em pertencer, em aderir a uma promessa de salvação, mas nada garante que $o$ poder não exija cada vez mais altos preços, em nome do bem, posse que nos diga que temos um eu muito coerente.

"O mal é minoritário, uma intensidade que mina o todo social destruindo-lhe os elementos ou os seus bens - objectos, servos, significados." linguagens, que impede que os significados se estabilizem em cartilhas. Há, por outro lado, a crença de que precisamos
15. LLANSOL. Nós estamos de volta, p. 92-93.
EM TESE

\begin{abstract}
BELO HORIZONTE
\end{abstract}
v. 19

N. 2

AG0.-OUT. 2013

BETHONICO. Llansol, La Boétie, a servidão voluntária e a liberdade de escrever P. 226-237
16. LOPES. Teoria da despossessão, p. 8. 
17. LOPES. Teoria da despossessão, p. 8. produzir, de que precisamos falar, significar o tempo inteiro, cercando a dispersão, determinando-nos muito seguramente, construindo e desconstruindo castelos. Mas a escrita

[...] é um mal sublime: os bens que nos retira, e que se resumem na segura representação de um mundo e de um poder sobre ele, são substituídos por um mal (um bem? A distinção deixa de fazer sentido) maior: a doença do infinito. O inapresentável é o impossível que nos toma permitindo-nos ir além do que podemos ir, mostrando-nos que somos para além do que podemos conhecer de nós, diferentes do todo que nos imaginamos ser. ${ }^{17}$

A coerção do hábito, ao contrário, é o que não tem jeito, o que não vale a pena querer mudar, o que está e pronto, é mais fácil que seja assim para que não tenhamos que lidar com a mutação, a qual deformará concretamente o reconhecimento insensível da vida.

A escrita acadêmica, como força de ler as possibilidades do que está estagnado e de estar em contato com o movimento dos textos, anda muito paralisada por uma servidão voluntária. Digo isso por experiência e pelo diálogo com colegas sobre a dificuldade de escrever, pelo acanhamento generalizado em compartilhar ou discutir trabalhos no ambiente universitário, pelo esforço que se deve fazer para escutar as ideias de outros e também para escutar as próprias, e a interseção das próprias ideias com as de outros. Sublinho aqui a necessidade de exercitar-se o ser livremente, na academia ou não, apesar de qualquer hierarquia fantasmante.

Há uma liberdade como aprender a falar e aprender a fazer silêncio, pela imprevisibilidade do nosso trajeto de corpos que criam e trocam linguagens. "Creio que é uma dádiva muito grande que se faz ao texto de um outro: construir-lhe silêncio à volta." ${ }^{18}$ Não precisamos ser consumidores ou espectadores do tédio, podemos ser e somos produtores de nossas próprias realidades, no encontro vital com o acaso. Construir, usar, ler linguagens revela-se um horizonte mais amplo que os princípios de divisão social dos homens, à medida que nos permitimos escutar o que os fatos e o silêncio têm a dizer quando não temos mais nada conhecido, senão o corpo.

\section{A FORÇA DO IMPREVISÍVEL}

O que interessa é a diferença entre o que se espera e aquilo que acontece. $\mathrm{O}$ vazio que se faz a partir dessa diferença. Em liberdade não se trata de insistir em moldes organizativos que um absoluto nos deu à partida, mas de habitar o espaço em que tudo está horizontalizado, tudo pode ter o brilho da vida efetiva. Esse não-determinar está, por exemplo, nas práticas da escrita e da leitura vividas como experiências intensas que desestruturam o abuso sobre as subjetividades, já
18. LLANSOL: MENDES. O espaço edénico, p. 152
EM TESE
BELO HORIZONTE 
19. LLANSOL. Nós estamos de volta, p. 93.

20. LLANSOL. Um falcão no punho, p. 55. que "na linguagem dos homens, as palavras que nos libertam do Poder desde sempre lá se encontram disponíveis". ${ }^{19}$

Maria Gabriela Llansol convoca a escrita como um ofício manual, não uma atividade abstrata cercada por valores idólatras. A tarefa mais direta do artesão de escrita, que vive, cozinha, pensa, tateia, é a potência de libertação por meio das palavras de uma linguagem que todos os homens compartilham entre si. A diferença que o trabalho de escrita e de leitura estabelece está no valor que se dá às ligações que se fiam entre palavras e os mais diversos mundos. Aî está a afinidade entre escrita e poiesis - trazer alguma coisa à presença, criar -, pois esse fazer não se destina ao sustento material, diríamos mesmo que não se destina a nada que se possa comprar.

Não há livros como objetos de criatividade a ser consumida, "não há literatura. Quando se escreve só importa saber em que real se entra, e se há técnica adequada para abrir caminho a outros." ${ }^{20}$ Criar não é uma produção no sentido comumente utilizado no capitalismo. A escrita, ofício de sulcar mundo e relação com palavra, jamais poderá fazer parte de uma divisão entre trabalho intelectual e trabalho manual, uma vez que, sonhada por um corpo desejante, “[...] é uma manifestação da vida em excesso em relação aos domínios económico e social. Falar pois de 'trabalho poético' é introduzir a dimensão do agir, da práxis, sem no entanto dissolver esse fazer na noção comum de trabalho". ${ }^{21}$

Abrindo o pulmão para aspirações, criar é exercitar a liberdade de investigar o que se quer, de realizar a sua concretização em objeto, que não se reduzirá jamais à satisfação de uma falta, por mais que se possa querer agarrar como produto. "Escrever vislumbra, não presta para consignar."2 Alquimia daquele que abraça as próprias condições de seu fazer fazendo, resistindo sem ser obrigado a nada.

Da convicção de que não há nenhuma essência (natural) do humano, de que o que o determina é o seu agir, sempre local, circunstancial, decorre que nenhum mecanismo se pode substituir ao empenhamento de cada um, à sua maneira de ser autônomo num sistema de relações de que cria a necessidade. [...] Não sendo decorrente nem de uma imposição natural ou social, nem da "liberdade" de um sujeito, pois não se limita à vontade, à consciência, o trabalho poético nunca se esgota numa relação sujeito-objecto. O que não nega que decorra de uma liberdade como modo extremo, exterior a qualquer determinismo, exterior à própria Lei que separa o interior e o exterior. Por isso não corresponde a relações de obediência/ transgressão, em que a excepção serve para confirmar a Lei, mas sim de resistência. ${ }^{23}$
21. LOPES. Anomalia poética, $\mathrm{p}$ 252.

22. A. BORGES. Eu leio assim este livro, p. 10

2. LOPES. Anomalia poética, p. 252-253. 
24. DERRIDA citado por LOPES Anomalia poética, p. 250

\section{NANCY. Resistência da} poesia, p. 34.
O que no objeto criado mais importa jamais estará discriminado. Não está na forma, "a forma fascina quando já não se tem a força de compreender a força no seu interior. Quer dizer, de criar". ${ }^{24} \mathrm{~A}$ força não está tampouco numa essência, mas no indizível e no mistério do corpo-coração, sem limites para o intenso, ou mesmo para desintensificar. A não-teleologia da criação abre para uma convivência com o que pode não ser, com o incerto que continua mesmo depois da explosão do criado. Esses olhos fechados que assistem micropartículas de cor se moverem no seu próprio escuro.

\section{O CORPO E A ESPESSURA DAS PALAVRAS PARA NADA}

A invisível libertação por meio das palavras potencializa-se não pelo que nelas encontramos de denotação, ou de desconstrução, mas por algo primitivo. Um desde sempre que permeia a vida do instrumento mais utilizado cotidianamente, a linguagem verbal. A liberdade não é uma transgressão, não faz nada "para" concluir algo. A escrita ou a poesia são aqui convocadas a uma resistência ao discurso como "injunção paranóica de constituir o verdadeiro constituindo-se a si mesmo, assumindo-se e absorvendo-se na sua auto-constituição e na sua auto-compreensão". ${ }^{25}$

A resistência do texto não se encontra diretamente na forma, mas na potência deformadora, espessura infinita e todavia, imediata que permeia no vivo a escrita, a leitura e a releitura. A resistência está no próprio corpo que se compromete com esses fazeres como práticas de livre sentido.

[...] as palavras resistem, elas têm uma espessura, sua existência densa exige, para que elas sejam compreendidas, uma intervenção corporal, sob a forma de uma operação vocal: seja aquela da voz percebida, pronunciada e ouvida ou de uma voz inaudível, de uma articulação interiorizada. É nesse sentido que se diz, de maneira paradoxal, que se pensa sempre com o corpo: o discurso que alguém me faz sobre o mundo (qualquer que seja o aspecto do mundo sobre o qual ele me fala) constitui para mim um corpo-a-corpo com o mundo. O mundo me toca, eu sou tocado por ele; ação dupla, reversível, igualmente válida nos dois sentidos. Essa ideia, eclipsada durante um certo tempo, renasce hoje, em uma espécie de volta do rechaçado $[. . .]^{26}$

Eterno retorno do desde sempre, o corpo, "que corpo é esse? um corpo provisório como todo corpo é." ${ }^{27}$ Procurar escutar o sentir da forma como se sente, honestamente, reconhecendo que determinados moldes podem ser ou não usados, é um contato intensamente direto que se pode ter com o mundo, ainda que fugidio. Uma ética que é, indefinidamente, estética.

"Os valores passaram à clandestinidade", diz um grafite em um muro de Lisboa. $\mathrm{Na}$ escola das sociedades de controle somos ensinados a nos sentarmos inertes. Depois, o corpo
26. ZUMTHOR. Performance, recepção e leitura, p. 77

27. NEUPARTH. passear as mãos pela geografia do corpo, p. 12.
EM TESE
BELO HORIZONTE
v. 19
N. 2
AG0.-OUT. 2013
BETHONICO. Llansol, La Boétie, a servidão voluntária e a liberdade de escrever P. 226-237 
28. LLANSOL. Carta aberta a Eduardo Prado Coelho, Sintra 25 de Novembro de 1999. Sintra Eça Espaço Llansol, na revista virtual Ciberkica, na revista virtual Ciberkiosk, en março de 2000, e náo se encontra mais no ar. Houve uma publicação parcial na revista $L e r$ $n^{\circ} 48$, Inverno de 2000. volta como estranho. Algo que se tornou tão indiferenciadamente parte de nós que se confunde com o escondido, assombrando-nos com o seu vigor, quando se faz visivelmente vivo.

A escrita e a leitura como atividades intensas são vividas a partir de um corpo não abstrato, mas singular como um nome próprio e imprevisível como o que emerge da voz práticas "privadas", marginais às instituições acadêmicas, que não raro burocratizam a relação com os textos, ou seja, automatizam irrefletidamente o corpo. Como nos diz Llansol em uma carta aberta a Eduardo Prado Coelho, em que fala sobre a condição de sua obra no meio literário português:

No quadro da literatura "nacional", serei sempre a esotérica de serviço. A minha literatura e a dos que escrevem no campo em que me situo será sempre marginal, intemática, incompreensível. [...] Esta cultura pura e simplesmente não quer a minha obra, não sabe o que fazer dela, excepto em termos privados. $\mathrm{O}$ número de pessoas "cultas" da nossa praça que a leem (algumas citaram-me páginas inteiras de cor) e são incapazes de a nomear no espaço público é propriamente aterrador. E, mesmo em privado, procuram silenciar o pensamento que ela veicula Ou seja, eles próprios, no sistema da dupla cultura, colocam aquele texto na esfera do privado, não abrindo espaço para que eu possa intervir, não como marginal mas como ser humano que criou uma perspectiva que, em privado, lhes é útil. ${ }^{28}$
Se os princípios organizadores da sociedade não lograram como deveriam, ir com o texto à rua ou à escola significaria desenhar uma potente margem de resistência. Essa política tem outra relação com as palavras: sabe que os mecanismos de aprisionamento recaem sobre a própria sensibilidade, cuja vivência obrigatoriamente silenciada cria histórias balbuciadas sob disfarces incidindo uma ferida na comunidade humana.

Essa ferida não separa os ricos dos pobres, nem os opressores dos oprimidos, nem se traduz em níveis de rendimento, mesmo se historicamente a divisão a que me refiro tomou essas formas várias de disfarce. Não, essa ferida separa os atentos dos distraídos, os mornos dos intensos, os necessitados de misericórdia e os orgulhosos. Se, no que até hoje escrevi, algo deva ficar, desejaria que fosse isso:

Há uma história silenciosa dos intensos que, porque necessitados de misericórdia, não impuseram aos seus congêneres as cadeias de explicação, nem miragens para o desejo. Gostaria que sobrevivesse a afirmação que nós somos epifanias do mistério, e mistério que nos nossos balbuciamentos se desenrola. ${ }^{29}$

O intenso mostra a sua cara publicamente sem as expectativas impostas por um coletivo que supostamente sabe o que é comunicar-se. Ele emerge com tanto gosto que não se explica, não se interessa em agradar com miragens, sem saber mesmo se algo do que faz vai ficar. O intenso não é
29. LLANSOL. Encontro-me no novo. In: Lisbaleipzig 1: 0 Encontro Inesperado do Diverso, p. 85.
EM TESE
BELO HORIZONTE v. 19 
30. “[...] a espécie humana/ Não pode suportar muita realidade." Trad. de Gualer Cunha, p. 27. de Gualter Cunha.

31. LLANSOL. Onde Vais, DramaPoesia?, p. 94. uma essência do eu. Nele, aquilo que emerge é importante principalmente no momento em que acontece - epifania, manifestação reveladora, volátil, clarão, balbuciamento, pois não se pode estar com a verdade sem contar com uma penumbra. "[...] human kind/ Cannot bear very much reality." Mistério murmurado da prática de uma escuta que lida com restos de uma comunicação viva, pulsante, em movimentos de reconhecimento e não-reconhecimento, delineamento e indiferenciação:

quantas vezes falamos sem nada dizermos do que é real, mas sem desconhecermos um só instante essa realidade. Um entretém.

Quantas vezes sabemos que a alma está pairando no rebordo dos dedos pousados na mesa. E continuamos como se não tivéssemos a alma que, de facto, temos.

Quantas vezes os nossos olhares se trocam. Quase sempre vão e voltam

e, quando não voltam, quantas vezes nos esquecemos de libertar o segredo da posse. E é de propósito que o fazemos.

Sabemos que, em nada, nos podemos mentir

e, mesmo mentindo, o outro conhece a verdade e acredita na mentira que estamos trocando. E é não é por mal. ${ }^{31}$

O que de fato somos, essa coisa difícil provisória desde sempre, se esconde em meio a negociações de posse que não nos colocam em contato, garantias do suposto conforto de que as coisas permaneçam como estão - "a apropriação é sempre identitária, modo de reforçar o estabelecido". ${ }^{32}$ Adia-se a realidade, que não para, permeada de silêncios e ruídos.

E é de propósito que o fazemos. Aqui está o caráter paradoxal dos limites de um texto que pretenda abordar uma obra como a de Llansol, no espaço que criamos na academia. Como abordar uma escrita que tem uma preocupação com o controle das palavras, o qual chama de impostura da lingua, hipocrisia que assola a enunciação do nosso ser como ele for? Nenhuma liberdade humana se contentará com uma formatação. Ainda que seja totalmente viável encontrar formas de dizer por ensaio ou dissertação, tratando-se de práticas de linguagem e resistência, em quais espaços de encontro temos que insistir? E quais estão por criar?

Toda análise é uma intervenção - o elemento de um conjunto nunca poderá abarcar esse mesmo conjunto, estando, portanto, em corpo-a-corpo com ele. Mas não foram considerados ainda os potenciais interventivos de que podemos nos servir como vidas que escrevem/criam sobre criação, ou seja, pessoas que escutam nas práticas estéticas (ou, como sugere Llansol, artesanais), um recomeço, um abrir-se de portas para que outros possam fruir e dialogar à sua maneira, em busca do rigor da própria inclinação, não em troca de protocolos.
32. LOPES. Anomalia poética, $\mathrm{p}$ 254.
EM TESE
BELO HORIZONTE
V. 19
N. 2
AG0.-OUT. 2013
BETHONICO. Llansol, La Boétie, a servidão voluntária e a liberdade de escrever P. 226-237 
Diante do esmagamento do singular, dos amordaçamentos da história por uma suposta unanimidade, torna-se urgente experimentar dizer nada. É urgente experimentar fazeres para nada. Trocar com o outro, comunicar sem resultados, encontrar sem procurar - atividades que, se querem conhecer gente, fazer pelo humano, encontram na falta de objetivo a sua maior pertinência.

\section{REFERÊNCIAS}

A. BORGES. Eu leio assim este livro. In: LLANSOL, Maria Gabriela. O livro das comunidades - Geografia de rebeldes I. Lisboa: Relógio d'Água, 1999

A. BORGES. Texto para a restante vida. In: LLANSOL, Maria Gabriela. A restante vida -- Geografia de rebeldes II. Porto: Afrontamento, 1982.

BLOCH, Ernst. "Princípio da esperança: uma enciclopédia dos desejos sonhados pela humanidade". In: MÜNSTER, Arno (ed.). Sonhos diurnos sobre o porte íntegro. Seis entrevistas com Ernst Bloch. [Tagträume vom aufrechten Gang. Sechs Interviews mit Ernst Bloch. Frankfurt, Suhrkamp, 1977.] Tradução de João Barrento. In: BLOCH et al. À Beira do rio da esperança. Serra de São Mamede, 2010. Não publicado.

CASTRO, Juliana Cabral Junqueira de. Que sonho vamos nós sonhar que nos sonhe? In: BRANCO, Lucia Castello; ANDRADE, Vania Baeta (Orgs.). Livro de asas - para Maria Gabriela Llansol. Belo Horizonte: Editora UFMG, 2007. p. 67-78.
CLASTRES, Pierre. Liberdade, infortúnio, inominável. In: LA $B O E T I E$, Etienne de. Discurso sobre a servidão voluntária. Trad. Manuel João Gomes. Lisboa: Antígona, 1997.

ELIOT, T.S. Quatro quartetos. Trad. de Gualter Cunha. Lisboa: Relógio d'Água, 2004

FREUD, Sigmund. O estranho [1919]. In: FREUD, Sigmund. História de uma neurose infantil. Rio de Janeiro: Imago, 1996. p. 233-270. (Edição standard brasileira das obras psicológicas completas de Sigmund Freud, 17.)

JOAQUIM, Augusto. Nesse lugar. In: BRANCO, Lucia Castello; ANDRADE, Vania Baeta (Orgs.). Livro de asas - para Maria Gabriela Llansol. Belo Horizonte: Editora UFMG, 2007. p. 193225.

LA BOÉTIE, Étienne de. Discurso sobre a servidão voluntária. Trad. Manuel João Gomes. Lisboa: Antígona, 1997.

LACOUE-LABARTHE, Philippe. O Paradoxo e a mimese. In LACOUE-LABARTHE, Philippe. FIGUEIREDO, Virginia de Araujo PENNA, João Camilo (Orgs.). A imitação dos modernos. Trad. João Camilo Penna et al. São Paulo: Paz e Terra, 2000.

LISPECTOR, Clarice. A Paixão Segundo GH. Rio de Janeiro: Rocco, 1998.

LLANSOL, Maria Gabriela. Carta aberta a Eduardo Prado Coelho, Sintra, 25 de Novembro de 1999. Associação Espaço Llansol, Sintra. Inédito. 
LLANSOL, Maria Gabriela. Um falcão no punho - Diário I. 2ª ed. Lisboa: Relógio d’Água, 1998.

LLANSOL, Maria Gabriela. Encontro-me no novo. In: LLANSOL Maria Gabriela. Lisbaleipzig 1: o encontro Inesperado do Diverso. Lisboa: Rolim, 1994.

LLANSOL, Maria Gabriela; MENDES, João. O espaço edénico. In: LLANSOL, Maria Gabriela. Na casa de julho e agosto. Lisboa: Relógio d'Água, 2003. p. 141-168.

LLANSOL, Maria Gabriela. Nós estamos de volta. In: LLANSOL, Maria Gabriela. Lisboaleipzig 1: o encontro inesperado do diverso. Lisboa: Rolim, 1994.

LLANSOL, Maria Gabriela. Onde vais, drama-poesia? Lisboa: Relógio d'Água, 2000.

LOPES, Silvina Rodrigues. Anomalia poética. Lisboa: Vendaval, 2006.

LOPES, Silvina Rodrigues. Teoria da des-possessão. Lisboa: Black Sun Editores, 1988.

NANCY, Jean-Luc. Resistência da poesia. Trad. Bruno Duarte. Lisboa: Vendaval, 2005.

NEUPARTH, Sofia. passear as mãos pela geografia do corpo. In: práticas para ver o invisível e guardar segredo (estudo do corpo e do movimento escrito em estado de dança). Lisboa: c.e.m. - centro em movimento, 2009.

ZUMTHOR, Paul. Performance, recepção e leitura. Trad. Jerusa Pires Ferreira e Suely Fenerich. São Paulo: Cosac Naify, 2007.

EM TESE

BELO HORIZONTE

v. 19

N. 2

AG0.-OUT. 2013

BETHONICO. Llansol, La Boétie, a servidão voluntária e a liberdade de escrever P. 226-237 